ISSN 1981-416X

Licenciado sob uma Licença Creative Commons

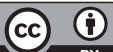

\title{
Dispositivos de accountability na reforma da educação básica brasileira: tendências em curso $^{1}$
}

\author{
Accountability tools in the reform of Brazilian basic \\ education: current trends
}

\begin{abstract}
Herramientas de rendición de cuentas en la reforma de la educación básica brasileña: tendencias actuales
\end{abstract}

\section{Marilda Pasqual Schneider*}

Universidade do Oeste de Santa Catarina, Joaçaba, SC, Brasil

\section{Resumo}

Demandas recorrentes pela utilização de dispositivos de accountability na educação têm levado pesquisadores da área a enveredar seus estudos por esse tema. No intuito de contribuir com o debate, constitui objetivo deste texto empreender uma análise em torno do vocabulário da reforma na educação básica brasileira, de modo a perspectivar tendências em curso a partir da apropriação de expressões e mecanismos atualmente associados à accountability educacional. Partindo do pressuposto de que os documentos da reforma procuram criar o que Jameson (1997) denomina de hegemonia discursiva em torno das

\footnotetext{
${ }^{1}$ Pesquisa realizada com apoio financeiro do CNPq, nas modalidades MCTI/Universal. Agradeço as contribuições do bolsista de Iniciação Científica, Samuel Miguel, pelo trabalho de levantamento dos dados da pesquisa que resultou neste artigo.
}

*MPS: Doutora em Educação, e-mail: marilda.schneider@unoesc.edu.br 
mudanças requeridas, o percurso metodológico compreende levantamento de documentos que permitem traçar o caminho dessas mudanças na educação básica e análise de palavras e expressões neles recorrentes. Os resultados evidenciam construção de uma rede discursiva no vocabulário da reforma que, no seu conjunto, vaticina mudança nos modos de regulação da educação básica, pautada na participação, transparência e controle social. Contrariando a perspectiva de uma política para uma educação básica democrática, disseminada nos documentos analisados, a interpretação das significações do vocabulário concordam com características para uma accountability gerencial, a partir da qual seja possível alcançar eficiência educacional e competitividade internacional por meio de reformas alinhadas com princípios da new public management.

Palavras-chave: Políticas educacionais. Reforma da educação básica. Vocabulário da reforma. Accountability.

\section{Abstract}

Recurrent demands for the use of accountability tools in education have led researchers to undertake studies on this topic. Aiming to contribute to this debate, the article's purpose is to undertake a vocabulary analysis of the Brazilian educational reform, in order to verify current trends of appropriation of vocabulary and the mechanisms currently associated with educational accountability. Assuming that the reform documents seek to create what Jameson (1997) calls discursive hegemony around the required changes, our methodological approach comprises mapping documents that allow us to trace these changes in basic education and also analyzing recurrent terms and expressions. Results show the construction of a discursive network in the reform vocabulary that, as a whole, predicts a change in the paths of regulation of basic education, based on participation, transparency and social control. While contradicting a perspective of a policy for a democratic basic education, disseminated in the documents analyzed, the interpretation of the meanings of the vocabulary is consistent with characteristics for a managerial accountability, from which it is possible to achieve educational efficiency and international competitiveness through reforms aligned with principles of the new public management. 
Keywords: Educational policies. Reform of basic education. Vocabulary of the reform. Accountability tools.

\section{Resumen}

Las demandas recurrentes para el uso de herramientas de rendición de cuentas en la educación han llevado a los investigadores a realizar estudios sobre este tema. Con el objetivo de contribuir a este debate, el propósito del artículo es realizar un análisis de vocabulario de la reforma educativa brasileña, a fin de verificar las tendencias actuales de apropiación de vocabulario y los mecanismos actualmente asociados a la rendición de cuentas en la educación. Suponiendo que los documentos de la reforma buscan crear lo que Jameson (1997) Ilama de hegemonía discursiva en torno a los cambios necesarios, nuestro enfoque metodológico comprende el mapeo de documentos que nos permiten rastrear estos cambios en la educación básica y también analizar términos y expresiones recurrentes. Los resultados muestran la construcción de una red discursiva en el vocabulario de la reforma que, en su conjunto, predice un cambio en la manera de regulación de la educación básica, basada en la participación, la transparencia y el control social. Contrariamente a la perspectiva de una política para una educación básica democrática, difundida en los documentos analizados, la interpretación de los significados del vocabulario es coherente con las características de una redición de cuentas gerencial, desde la cual sea posible lograr eficiencia educativa y competitividad internacional mediante reformas alineadas con los principios de la nueva gestión pública.

Palabras clave: Políticas educativas. Reforma de la educación básica. Vocabulario de la reforma. Accountability.

\section{Introdução}

A accountability em educação é tema em franca ascensão no quadro das políticas educacionais das últimas décadas, em países centrais. 
Ainda que sua presença no campo da administração pública, mormente na ciência política, esteja razoavelmente consolidada, a entrada na educação, especialmente em países latino-americanos, como é o caso do Brasil, pode ser considerado fenômeno recente.

Conceitualmente controversa, uma vez que sua heurística depende da área de conhecimento a qual se filia e da aplicação que dela se faz, a expressão tem sido frequentemente associada à ideia de responsabilização e prestação de contas ou, ainda, consoante sua aplicação prática, por ambas as expressões. Na educação, a accountability vem sendo utilizada em conexão com políticas de avaliação por meio das quais tende a se responsabilizar escolas, docentes e comunidade escolar pelos resultados educacionais alcançados por estudantes em exames externos aplicados em larga escala.

Conquanto sejam essas as vinculações mais habituais, não se pode perder de vista que aplicações empíricas da accountability em áreas como as aqui referidas permitem conectar o tema com outras expressões cujo significado pode remeter a perspectivas teóricas distintas e cujas formulações práticas podem ser contraditórias ou mesmo paradoxais entre si. É o caso, por exemplo, de termos tais como participação, transparência, controle social, fiscalização, democracia, dentre outros, implicados na implementação ou aprofundamento de dispositivos de accountability com interesses e finalidades muitas vezes controversos. Por isso, quando nos referimos a esse tema é necessário ter em conta a amplitude do conceito, o seu léxico e seus usos práticos.

No Brasil, o tema da accountability educacional tornou-se recorrente a partir das mudanças operadas no Sistema de Avaliação da Educação Básica (Saeb), em 2005, por meio do qual se passou a realizar avaliações censitárias em todas as escolas públicas do país. Admite-se, no entanto, que, do ponto de vista da responsabilização, a aplicação empírica de dispositivos de accountability na educação básica brasileira foi efetivamente facilitada com a criação, em 2007, do Índice de Desenvolvimento da Educação Básica (Ideb). Pela via desse indicador, foram atribuídas 
metas bianuais às escolas públicas cuja aferição passou a ser o desempenho dos estudantes nos exames do Saeb.

Com base no cenário brevemente esboçado e no pressuposto de que as reformas educacionais incursionadas a partir dos anos de 1990 tomam como marco referencial a conformação da educação às leis que regem o mercado e a iniciativa privada, constitui objetivo deste estudo empreender uma análise do vocabulário da reforma educacional brasileira de modo a verificar em que medida os textos de política para a educação básica incorporam terminologias conexas aos dispositivos que respondem por medidas de accountability. Intentamos, com o estudo, deslindar tendências no uso de um determinado vocabulário na implementação das reformas educacionais.

Partindo do pressuposto de que os documentos da reforma procuram criar o que Jameson (1997) denomina de hegemonia discursiva em torno das mudanças requeridas, o percurso metodológico compreende mapeamento de documentos que sintetizam políticas para a educação básica e análise de vocábulos ou expressões neles recorrentes.

O estudo é regrado por um conjunto de técnicas que informam a análise de conteúdo, nos termos referidos por Bardin (1995). Segundo discorre a autora, o desenvolvimento de uma análise de conteúdo compreende três momentos articulados entre si: pré-análise, exploração do material e, por fim, tratamento dos resultados e interpretações. Consoante esse detalhamento, o primeiro momento compreendeu delimitação do campo de pesquisa e escolha dos documentos que constituiriam o corpus. Tendo em vista a recente entrada do tema da accountability na política educacional brasileira, optamos por selecionar documentos produzidos no período compreendido entre os anos de 2005 e 2014 e que, a nosso ver, oferecem, em alguma medida, pistas sobre o caminho da reforma, bem como sobre a formulação da política para a educação básica em nosso país. O recorte desse período teve em vista incluir, entre os documentos analisados, a 
Portaria que instituiu o Saeb, em 2005, e a Lei que aprovou o último Plano Nacional de Educação (PNE 2014-2024)².

O segundo momento consistiu em preparar o material para a análise propriamente dita. Nessa direção, os documentos selecionados foram categorizados por data de publicização, finalidade e expressões recorrentes. Importa destacar que a codificação do material foi precedida pela formulação de hipóteses e pela delimitação de palavras-chave a partir das quais se deu, em momento posterior, a exploração de termos recorrentes nos e entre os documentos. Constituíram palavras-chave os seguintes vocábulos, comuns na literatura sobre a accountability: participação, transparência, controle social, fiscalização, publicização, prestação de contas, responsabilização, sanção e bonificação. Embora tenhamos consciência de que esse conjunto não encerra o léxico implicado na ideia de accountability, acreditamos ser suficientemente representativo do vocabulário da reforma da educação básica brasileira no período amostrado.

Por fim, de posse dos resultados obtidos com a exploração do material, o último momento da análise compreendeu operações quanti-qualitativas de síntese, produção de inferências e interpretação teórico-pragmática das tendências no uso desse vocabulário.

2 Considerando o recorte temporal adotado e os objetivos da pesquisa traçados, constituíram o corpus documental de análise: (i) Portaria no 931, de 21 de março de 2005 - Institui o Sistema de Avaliação da Educação Básica (Saeb); (ii) Decreto no 6.094, de 24 de abril de 2007 - Dispõe sobre a implementação do Plano de Metas Compromisso Todos pela Educação; (iii) Resolução no 5, de 17 de dezembro de 2009 - Fixa as Diretrizes Curriculares Nacionais para a Educação Infantil; (iv) Resolução no 14, de 13 de julho de 2010 - Fixa as Diretrizes Curriculares Nacionais Gerais para a Educação Básica; (v) Resolução no 7, de 14 de dezembro de 2010 - Fixa as Diretrizes Curriculares Nacionais para o Ensino Fundamental de 9 (nove) anos; (vi) Resolução no 2, de 30 de janeiro de 2012 - Fixa as Diretrizes Curriculares Nacionais para o Ensino Médio; e (vii) Lei no 13.005, de 25 de junho de 2014 e Anexo I da Lei - Aprova o Plano Nacional de Educação - PNE e dá outras providências. 


\section{Escopo e abrangência da accountability}

Um estudo realizado entre 2016 e 2017 sobre o tema ${ }^{3}$ permitiu constatar que o conceito de accountability padece de certa instabilidade semântica. Frequentemente remetido à ideia de prestação de contas ou responsabilização, trata-se, antes de tudo, de um vocábulo de amplitude plural, arbitrado por uma variedade de teorias muitas vezes contraditórias entre si, e cujo escopo e abrangência estão diretamente implicados nas finalidades que lhe são atribuídas e nos usos a que se destina.

Bovens (2006, p. 3, tradução livre), que interpreta o fenômeno pelas lentes da administração pública, dirá que a accountability implica "uma relação entre um ator e um fórum", na qual cabe ao ator - governante ou agente público de uma instituição - explicar e justificar sua conduta perante este fórum e arcar com as consequências, positivas ou não. Ao fórum - agente externo com função devidamente institucionalizada - cabe julgar a referida conduta e atribuir sanções, se for o caso. As sanções, segundo o autor, poderão ter caráter institucional ou político, mas sempre estarão submetidas às determinações legais previstas em atos normativos.

Na perspectiva defendida, a accountability abrange relações institucionais de fiscalização e imputação de sanções. Logo, seu escopo restringe-se aos espaços formais de controle da ação pública, não podendo ser incluídos mecanismos formais e informais não institucionalizados, tais como os meios de comunicação ou mesmo a sociedade civil. Diz respeito, portanto, aos atos institucionalizados de governos democráticos ou não. Harmonizam-se com a percepção desse estudioso alguns autores igualmente consagrados na literatura da administração pública, tais como Kenney (2003) e Manin, Przeworki e Stokes (2006), entre outros.

\footnotetext{
${ }^{3}$ Refiro-me a uma investigação em que se efetuou um mapeamento de autores recorrentes em artigos científicos disponibilizados no Portal de Periódicos Capes e das concepções de accountability referidas por esses mesmos autores.
} 
Detentor de uma visão mais abrangente, Schedler (2004, p. 8), investigador e cientista político do Centro de Investigación y desarollo de la Educación do Chile (Cide), dirá que a accountability reflete preocupação "[...] com freios e contrapesos, pela supervisão e pela restrição de poder." A concepção desse investigador circunscreve a accountability ao âmbito da responsabilidade pública, voluntária ou regida por lei, a partir da qual a prestação de contas constitui um direito, da sociedade em geral, de obter informações (respostas e justificativas) sobre a conduta pública dos representantes políticos eleitos pelo voto do povo.

Para a realização de uma ação de accountability, Schedler (2004) confere a necessidade de se levar em conta três elementos: a informação, a justificação e a imposição (sanção). Enquanto os dois primeiros estariam sustentados pela ideia de obrigação de prestação de contas, o último remeteria à atribuição de responsabilidades. Nesses elementos estaria, pois, vaticinada a necessária articulação entre prestação de contas e responsabilização nos atos de accountability. Concordam com essa perspectiva Malena, Forster e Singh (2004), Vera e Lavalle (2012), O’Donnell (1998), entre outros.

Especialmente O’Donnell desenvolve uma teoria a partir da qual existem duas possibilidades de accountability, uma vertical e, a outra, horizontal. A accountability vertical é atribuída pelo autor a uma ação praticada essencialmente por meio do voto, em países democráticos, a partir do qual "[...] os cidadãos podem punir ou premiar um mandatário votando a seu favor ou contra ele ou os candidatos que apoie na eleição seguinte" (O’DONNELL, 1998, p. 28).

Já, a horizontal, é considerada aquela realizada por

[...] agências estatais que têm o direito e o poder legal e que estão de fato dispostas e capacitadas para realizar ações, que vão desde a supervisão de rotina a sanções legais ou até o impeachment contra ações ou emissões de outros agentes ou agências do Estado que possam ser qualificadas como delituosas (O’DONNELL, 1998, p. 41). 
Nessa classificação, nota-se uma restrição quanto ao escopo da accountability, apesar de, na dimensão horizontal, serem considerados agentes de accountability não apenas as agências e os órgãos de fiscalização, mas também o judiciário. A restrição ocorre em vista de o autor considerar que apenas atores institucionais podem exercer o papel de agentes de controle e, tão somente, se lhes for atribuída a função de fiscalizar e punir. Já, na dimensão vertical, o controle da ação dos governantes ocorre majoritariamente pelo processo eleitoral, considerado pelo autor um dos principais mecanismos para uma accountability promovida pela sociedade civil.

Pesquisadores tais como Moreno, Crisp e Shugart (2003) e Schedler (2004), discordam da posição de O'Donnell sobre o que pode ou não ser considerado um ato de accountability em vista de a considerarem excessivamente restritiva frente às possibilidades de ramificação do conceito. Apesar disso, a classificação proposta pelo autor tem sido referida por inúmeros estudiosos que, conforme alude Ceneviva (2006, p. 5), reconhecem o pioneirismo de O’Donnell "na distinção e conceituação de diferentes formas de accountability."

Em outra direção ainda, Afonso (2010), estudioso português que focaliza o tema a partir das lentes da sociologia da educação, dirá que um sistema ou modelo completo de accountability compreende um processo dinâmico e integrado entre prestação de contas, responsabilização e avaliação. Quanto à prestação de contas, atribui uma dimensão informativa e argumentativa, à responsabilização confere função de imputar responsabilidades e determinar consequências e, à avaliação, a de permitir comparação crítica entre as duas etapas.

Portanto, para esse autor, um sistema completo de accountability terá a avaliação como uma das dimensões associadas à prestação de contas e à responsabilização, podendo ela (a avaliação) ocorrer antes, durante e ou depois das demais dimensões. Excluindo-se qualquer uma das dimensões do processo de construção do modelo, estaríamos, segundo sua percepção, diante de formas parcelares e não completas de accountability. Ainda que a característica intrínseca de cada uma das expressões seja considerada 
como alinhada a perspectivas político-democráticas, o autor defende que a função que lhes for imputada, o uso que delas se faz e as finalidades atribuídas é que determinariam a teoria, o escopo e a abrangência que orientam qualquer modelo de accountability.

Também adepto à inclusão da avaliação como um dos ingredientes de uma accountability na educação, Nigel Brooke, pesquisador convidado da Universidade Federal de Minas Gerais, traduz o termo simplesmente como responsabilização. Para o autor, a implantação de um sistema de responsabilização (accountability) educacional necessita da combinação de quatro ingredientes básicos, a saber:

1. a decisão por parte das autoridades de tornar públicas as diferenças de nível de desempenho das escolas (ingrediente autoridade); 2 . O uso de testes ou procedimentos padronizados para fornecer este tipo de informação (ingrediente informação); 3. Os critérios para analisar esta informação e para determinar quais escolas têm melhor desempenho (ingrediente padrões); 4. Os critérios para a aplicação de incentivos ou sanções conforme os padrões estabelecidos (ingrediente consequências) (BROOKE, 2006, p. 380).

A despeito de admitir não ser a responsabilização por resultados da escola a única forma de accountability, reitera que:

[...] se os membros profissionais da comunidade escolar podem ser considerados responsáveis pela qualidade da experiência educativa sob seu controle direto, e se os resultados dessa experiência podem ser medidos objetivamente, então a avaliação do desempenho do aluno pode se tornar parte de um sistema de responsabilização que visa estimular a melhoria mediante a divulgação dos resultados da escola (BROOKE, 2006, p. 398).

Segundo a percepção do autor, não há problema em que a avaliação de desempenho do aluno constitua uma das dimensões de um determinado modelo de accountability educacional. Pelo contrário, consoante advoga, o uso desse dispositivo na educação poderia servir de 
estímulo para a melhoria da qualidade. Para que se cumpra essa finalidade, no entanto, há que se curvar à possibilidade concreta de a avaliação tornar-se mecanismo de controle da ação docente e do currículo escolar. Parece, pois, que a visão desse autor sobre o uso da avaliação em sistemas de accountability dista consideravelmente da percepção defendida por Afonso (2010).

Consoante demonstrado, diferentes perspectivas e pontos de vista compõem as explicações sobre accountability e o seu léxico. Mesmo quando há alguma aproximação quanto ao escopo e à abrangência não há, necessariamente, correspondência sobre as finalidades e os usos do conceito. É certo, porém, que este tema coaduna com discursos que advogam em favor da ampliação dos espaços de participação social e de transparência, combinados com o compartilhamento e a descentralização de responsabilidades, ainda que num cenário repleto de disputas políticas e ideológicas sobre as finalidades da educação na sociedade capitalista.

Admitindo-se a colonização do conceito de accountability por correntes ideológicas neoconservadoras e neoprodutivistas, é fato que, conforme destacam Schneider e Nardi (2015, p. 72), os sistemas nacionais de avaliação da educação básica estão a tornar-se "[...] a porta de entrada e o esteio de políticas ou sistemas formais de accountability, embora não se trate de um fenomenal estranho ao curso assumido pelas políticas educacionais filiadas à 'nova gestão pública'."

Nesse novo contexto, o uso de ferramentas de accountability pauta-se na ideia de amplo poder discricionário dos servidores públicos - eleitos ou contratados - na implementação de mudanças educacionais, de modo a produzir os efeitos esperados pela ideologia capitalista. Embora o interesse anunciado seja o de assegurar os resultados da ação governamental, há certo afrouxamento de normas procedimentais, especialmente no uso dos dispositivos de accountability. O controle externo é considerado necessário, porém enfatiza o imperativo de monitoramento, prestação de contas, transparência e responsabilidade dos funcionários públicos - administradores, gestores e docentes - perante os resultados logrados. 
Essas características coadunam com o contexto no qual se inserem as políticas educacionais na atual fase de desenvolvimento do capitalismo, a partir da qual, consoante demonstra Afonso (2009, p. 58), as reformas educativas são também entendidas

[...] como tentativas de resolução dos dilemas que o Estado moderno enfrenta devido, nomeadamente, a uma acentuada e crescente crise fiscal que ao tender ser mais duradoura ou permanente, contribui para tornar mais evidentes os problemas normais do Estado face às exigências contraditórias decorrentes dos processos de acumulação e legitimação (grifos no original).

Nesse contexto, figura o interesse de grupos hegemônicos de liberar o Estado de algumas responsabilidades, tais como a oferta e melhoria da qualidade da educação, repassando esse compromisso às escolas, docentes e comunidade escolar. O escopo da accountability volta-se, pois, à promoção de unidade nacional e à coesão social em torno de um projeto hegemônico de sociedade, em que a função social da educação subordina-se às demandas do capital.

É, pois, com base nessa tendência que o estudo do vocabulário adstrito à reforma da educação básica pode incitar aprimoramento do debate acadêmico acerca das estratégias engendradas pelo Estado para tornar legítimas certas mudanças educacionais empreendidas no curso das transformações estruturais.

\section{Vocabulário da reforma}

Qualquer análise de documentos que conformam a política educacional brasileira requer levar em conta mudanças históricas no uso do vocabulário. A esse respeito, é importante lembrar o que afirmam Shiroma, Campos e Garcia (2005, p. 428) sobre essas mudanças.

No início dos anos de 1990, predominaram os argumentos em prol da qualidade, competitividade, produtividade, eficiência, e eficácia; ao 
final da década percebe-se uma guinada do viés explicitamente economicista para uma face mais humanitária na política educacional, sugerida pela crescente ênfase nos conceitos de justiça, equidade, coesão social, inclusão, empowerment, oportunidade e segurança.

A vulgarização do vocabulário da reforma é, pois, uma das estratégias engendradas por produtores da política educacional brasileira tendo em vista facilitar a construção de uma hegemonia discursiva em torno das inovações tidas como necessárias ao novo contexto educacional. Alinhada às novas demandas da lógica capitalista, que focaliza a necessidade de adoção de um novo modelo de administração pública, a educação adquire centralidade. Porém, incorpora funções regradas pelas leis do mercado, tais como o controle por resultados e a descentralização de responsabilidades.

Tomando as ponderações das autoras aqui referidas, a análise do vocabulário a que se refere o texto em pauta levou em conta o número de vezes que cada expressão aparecia nos documentos eleitos para o levantamento e os recursos implícitos ou explícitos no amoldamento dos significados atribuídos no contexto discursivo do documento.

A Tabela 1 traz uma síntese dos resultados alcançados com o levantamento efetuado e a incidência, nos documentos analisados, das palavras-chave eleitas para o estudo. A distribuição dos documentos na Tabela 1 segue o critério de datação da publicação do referido documento.

Tabela 1 - Vocabulário da reforma da educação básica (2005-2014).

\begin{tabular}{|l|c|c|c|c|c|c|c|c|}
\hline Palavras-chave & $\begin{array}{c}\text { Portaria } \\
\text { Saeb }\end{array}$ & $\begin{array}{c}\text { Decreto } \\
\mathbf{6 . 0 9 4 / 2 0 0 7}\end{array}$ & $\begin{array}{c}\text { DCNs } \\
\text { Ed. Infantil }\end{array}$ & $\begin{array}{c}\text { DCNs } \\
\text { Gerais da } \\
\text { Ed. Básica }\end{array}$ & $\begin{array}{c}\text { DCNs Ens. } \\
\text { Fundamental }\end{array}$ & $\begin{array}{c}\text { DCNs } \\
\text { Ens. } \\
\text { Médio }\end{array}$ & $\begin{array}{c}\text { PNE } \\
\mathbf{2 0 1 4 - 2 0 2 4}\end{array}$ & TOTAL \\
\hline Participação & - & 4 & 13 & 8 & 5 & 2 & 19 & 51 \\
\hline Transparência & - & 1 & - & 2 & 2 & 1 & 4 & 10 \\
\hline Controle Social & - & 1 & 2 & - & - & - & 3 & 6 \\
\hline Fiscalização & - & - & - & - & - & - & - & - \\
\hline Publicização & - & - & - & - & - & - & - & - \\
\hline $\begin{array}{l}\text { Prestação de } \\
\text { contas }\end{array}$ & - & - & - & - & 1 & - & - & 1 \\
\hline Responsabilização & - & - & - & - & - & - & - & - \\
\hline Sanção & - & - & - & - & - & - & - & - \\
\hline Bonificação & - & - & - & - & - & - & - & - \\
\hline TOTAL & $\mathbf{0}$ & $\mathbf{6}$ & $\mathbf{1 5}$ & $\mathbf{1 0}$ & $\mathbf{8}$ & $\mathbf{3}$ & $\mathbf{2 6}$ & $\mathbf{6 8}$ \\
\hline
\end{tabular}

Fonte: Elaboração própria. 
Se considerarmos a recorrência das palavras-chave nos documentos analisados, é possível julgar pouco expressivas as evidências de uso de um vocabulário conexo aos dispositivos de accountability. Do conjunto, sobressai-se o termo participação, referido em seis documentos, e as expressões transparência, controle social e prestação de contas, estas com incidência menor no conjunto de documentos. No entanto, tendo em conta os propósitos das reformas, a discursividade dos documentos que materializam o conteúdo dessas palavras e o contexto político-econômico e social mais amplo no qual se inserem as reformas da educação básica, é possível constatar que a falta de evidências é apenas aparente.

Uma análise pormenorizada dos sentidos dos vocábulos recorrentes nesses documentos permite extrair importantes evidências. É o caso, por exemplo, do conceito de participação, referido mais vezes e no maior número de documentos (o que nos parece uma certa obviedade) ${ }^{4}$.

Sobre esse conceito, alguns estudiosos da ciência política, tais como Dahl (1989), O’Donnell (1998), Schedler (2004), dentre outros, reiteram a necessidade da disponibilização e do uso de dispositivos de accountability especialmente em países nos quais formas e instituições democráticas foram recentemente restauradas. A utilização de tais dispositivos seria justificada especialmente pela possibilidade de, por meio deles, a sociedade civil poder exigir que representantes do povo, eleitos pelo voto, e instituições governamentais prestem contas dos recursos públicos e, também, se responsabilizem pelos resultados alcançados. A participação da sociedade civil no controle da ação pública teria, pois, o propósito de levar os cidadãos a atuarem na definição de metas coletivas e na fiscalização da ação do Estado.

Referindo-se à arquitetura da participação em países da América Latina, Vera e Lavalle (2012, p. 105) destacam que, nesses países, “[...]

\footnotetext{
${ }^{4}$ A obviedade a que nos referimos deve-se ao fato de que, nas reformas educacionais das últimas duas décadas, a ideia de participação passou a ser a força motriz das mudanças requeridas em vista do pressuposto da gestão democrática evocada na Carta Magna, de 1988, e na Lei de Diretrizes e Bases da Educação (LDB 9.394, de 20 de dezembro de 1996).
} 
houve uma multiplicação de experiências participativas orientadas, implícita ou explicitamente, pelas noções de accountability e controle social democrático sobre atores políticos e políticas públicas." Dentre o repertório de experiências, citam alguns exemplos considerados emblemáticos da multiplicação de espaços de participação da sociedade civil em toda a região, quais sejam:

[...] órgãos colegiados para a definição e a fiscalização de políticas, para a elaboração de prioridades nas áreas de planejamento ou de alocação de gastos públicos, comitês participativos em diferentes níveis da administração pública, instituições eleitorais de caráter civil, observatórios cidadãos, comissões de vigilância, ouvidorias e supervisões (veedurías) regionais (VERA; LAVALLE, 2012, p. 106, grifo no original).

Em relação às experiências brasileiras, anotam que prefigura "[...] um regime de controles democráticos sociais amplo, policêntrico e capilar, com potenciais aliados estratégicos de controle horizontal dentro do Estado" (VERA; LAVALLE, 2012, p. 112). As experiências fazem parte da agenda do Estado e contam com agentes institucionais com forte controle institucional, mas com efeitos multiplicadores nas demandas da sociedade civil. Por conta dessas características, chamam atenção para o risco de hipertrofia dos mecanismos de participação e controle democrático no Brasil.

Importa destacar, nesse contexto, que o conceito de participação remete ao de democracia. Contudo, porque o termo é caracterizado pela ambiguidade e a imprecisão semântica, nas últimas décadas surgiram diferentes modalidades e tipos de participação com significados igualmente plurais. A utilização do conceito por correntes de pensamento filiadas a perspectivas ideológicas distintas, bem como a sua colonização, a partir de um viés instrumental e fortemente apelativo, vem favorecendo a banalização e o uso retórico do conceito. Especialmente na educação, em vista da imposição à implementação de uma gestão democrática no ensino público, tende a se expandir um tipo normativo e marginal de participação. 
Congruente às prescrições da Constituição Federal de 1998, nos documentos da política para a educação básica a participação compreende diferentes atores, dispositivos e finalidades, porém com alcance predominantemente intrainstitucional. Incluem, pois: pais ou responsáveis, no acompanhamento das atividades escolares dos filhos e na avaliação de docentes e gestores; comunidades escolares, no planejamento e na aplicação dos recursos, na definição do modelo de organização pedagógica e de gestão das instituições; redes municipais de ensino, para orientar políticas públicas e a práticas pedagógicas; profissionais da educação, alunos e seus familiares, para a formulação e o acompanhamento dos projetos políticos-pedagógicos, currículos escolares, planos de gestão e regimentos escolares; conselhos escolares e conselhos municipais de educação, considerados instrumentos autônomos de fiscalização na gestão escolar e educacional; representantes da comunidade educacional e da sociedade civil, nos processos de elaboração e adequação dos planos municipal, estadual e do Distrito Federal (BRASIL, 2007; 2009; 2010a; 2010b; 2014).

Como é possível verificar, a amplitude do conceito circunscreve as instâncias de participação aos espaços de gestão do pedagógico ${ }^{5}$. Além de se caracterizar por uma visão meramente normativa e instrumental, essa concepção não permite avançar para uma participação política que, consoante apontam Riscal e Gandini (2010, p. 50), tem como pressuposto a "mediação entre cidadania, vontade geral e soberania popular." Há muitas formas de participação política, mas a que é exercida por meio de uma ação coletiva, organizada e voltada à conscientização da necessidade de se buscar o bem comum é a que, segundo as autoras, favorecerá a transformação social.

Ainda que seja requerida a interferência da comunidade escolar em processos mais amplos, tais como no planejamento e na aplicação

\footnotetext{
${ }^{5}$ Ferreira (2008, p. 183) considera que a gestão do pedagógico constitui a "[...] centralidade do trabalho dos professores". Os professores são, portanto, os sujeitos da gestão do pedagógico, o que implica, segundo a autora, "adentrar cada vez mais no arcabouço epistemológico que fundamenta a práxis pedagógica."
} 
de recursos financeiros, conforme prevê a estratégia dezesseis da meta sete do $\mathrm{PNE}^{6}$, a forma de participação referida nos documentos analisados restringe-se aos limites da boa vontade e da ação colaborativa, com confluência na e sobre a escola. A evocação aos princípios de gestão democrática enseja um apelo sedutor e retórico à participação, nos termos referidos por Sá (2001), com alcance majoritariamente instrumental. Contraditoriamente, subjaz a esse alcance a ideia de a comunidade atuar na escola com os olhos do Estado atuando, inclusive, na fiscalização da gestão escolar, conforme demonstrado na estratégia cinco da meta dezenove do PNE:

19.5) estimular a constituição e o fortalecimento de conselhos escolares e conselhos municipais de educação, como instrumentos de participação e fiscalização na gestão escolar e educacional, inclusive por meio de programas de formação de conselheiros, assegurando-se condições de funcionamento autônomo (BRASIL, 2014).

Sob os auspícios do exercício da democracia, a ação política da participação depende dos atributos individuais dos membros da comunidade escolar, um ato singular que tende a reverberar uma ação passiva dos envolvidos no processo.

Assim como o sentido da participação, também os vocábulos transparência e controle social remetem à ação de agentes institucionais, nomeadamente os conselhos escolares, dos quais se requer controle quanto ao cumprimento das políticas públicas educacionais e aos princípios orientadores de uma escola democrática, e transparência dos órgãos públicos locais na utilização dos recursos aplicados em educação, mormente na destinação do Fundo de Desenvolvimento da Educação Básica

${ }^{6}$ Dentre a estratégias que compõem a meta 7 o PNE, a de número 7.16 indica: "apoiar técnica e financeiramente a gestão escolar mediante transferência direta de recursos financeiros à escola, garantindo a participação da comunidade escolar no planejamento e na aplicação dos recursos, visando à ampliação da transparência e ao efetivo desenvolvimento da gestão democrática" (BRASIL, 2014, grifos dos autores). 
(Fundeb), na abordagem do projeto político-pedagógico e nos processos avaliativos (BRASIL, 2007; 2010a; 2014).

Especialmente no tocante aos processos avaliativos, o documento que visa orientar as escolas para a implementação das diretrizes curriculares nacionais gerais para a educação básica preconiza que a transparência nos processos avaliativos visa assegurar "[...] a possibilidade de discussão dos referidos resultados por parte de pais e alunos, inclusive junto a instâncias superiores à escola, no sentido de preservar os direitos destes" (BRASIL, 2013, p. 124). Traduz-se, em tal documento, como uma atitude requerida dos profissionais da educação na condução dos processos educativos.

Por sua vez, o vocábulo controle social prospectiva a ação da sociedade em duas direções prioritárias: uma delas voltada ao compromisso das famílias para com as políticas educacionais; a outra, ao atendimento das metas de qualidade educacional.

Sobre a primeira, convém destacar sua aparição no Decreto $n^{\circ}$ 6.094/2007, que dispõe sobre a implementação do Plano de Metas Compromisso Todos pela Educação. Nesse documento, o vocábulo aparece em uma das diretrizes a serem observadas pelos municípios, estados da federação e Distrito Federal na implantação do referido Plano: "XXI - zelar pela transparência da gestão pública na área da educação, garantindo o funcionamento efetivo, autônomo e articulado dos conselhos de controle social" (BRASIL, 2007, p. 1). Não se trata, portanto, de uma ação requerida de toda a sociedade civil, mas do grupo que atua como representante da comunidade educacional local. Logo, reduz o conceito ao plano normativo.

Quanto à segunda direção, esta é mais facilmente percebida no documento do PNE, onde o vocábulo aparece articulado às metas que orientam cada uma das estratégias nas quais o termo é mencionado:

7.28) mobilizar as famílias e setores da sociedade civil, articulando a educação formal com experiências de educação popular e cidadã, com os propósitos de que a educação seja assumida como responsabilidade 
de todos e de ampliar o controle social sobre o cumprimento das políticas públicas educacionais;

19.2) ampliar os programas de apoio e formação aos (às) conselheiros (as) dos conselhos de acompanhamento e controle social do Fundeb, dos conselhos de alimentação escolar, dos conselhos regionais e de outros e aos (às) representantes educacionais em demais conselhos de acompanhamento de políticas públicas, garantindo a esses colegiados recursos financeiros, espaço físico adequado, equipamentos e meios de transporte para visitas à rede escolar, com vistas ao bom desempenho de suas funções;

20.4) fortalecer os mecanismos e os instrumentos que assegurem, nos termos do parágrafo único do art. 48 da Lei Complementar no 101, de 4 de maio de 2000, a transparência e o controle social na utilização dos recursos públicos aplicados em educação, especialmente a realização de audiências públicas, a criação de portais eletrônicos de transparência e a capacitação dos membros de conselhos de acompanhamento e controle social do Fundeb, com a colaboração entre o Ministério da Educação, as Secretarias de Educação dos Estados e dos Municípios e os Tribunais de Contas da União, dos Estados e dos Municípios (BRASIL, 2014).

Como sabido, a meta sete do PNE trata da qualidade da educação básica, cuja referência mais importante é o Ideb, definido para cada escola do país. Logo, parece óbvio que o controle esperado da sociedade frente às políticas públicas implica vigilância no atendimento às metas do referido indicador, ação também requerida dos conselhos escolares. A meta dezenove trata da gestão democrática e, a vinte, da utilização dos recursos públicos. Ao que tudo indica, nenhuma das direções prospectadas pelo documento, nas suas diferentes estratégias, vislumbra possibilidades de o controle ser exercido em uma perspectiva vertical, ou seja, da sociedade civil sobre a ação do Estado.

Finalmente, no que tange ao uso da expressão prestação de contas, referida em um único documento, esta conserva clara sintonia com os pressupostos que encerram o uso hegemônico da accountability na 
educação, ou seja, o que submete o conceito aos preceitos da gestão burocrática gerencial. Neles, ganha centralidade a avaliação com foco nos resultados educacionais.

Conforme aludido nas diretrizes curriculares nacionais para o ensino fundamental de nove anos:

A avaliação proporciona ainda oportunidade aos alunos de melhor se situarem em vista de seus progressos e dificuldades, e aos pais, de serem informados sobre o desenvolvimento escolar de seus filhos, representando também uma prestação de contas que a escola faz à comunidade que atende. Esse espaço de diálogo com os próprios alunos - e com as suas famílias, no caso do Ensino Fundamental regular - sobre o processo de aprendizagem e o rendimento escolar que tem consequência importante na trajetória de estudos de cada um, precisa ser cultivado pelos educadores e é muito importante na criação de um ambiente propício à aprendizagem (BRASIL, 2010b).

Como observado, não apenas as avaliações no âmbito do Saeb devem constituir ferramenta de prestação de contas por parte da escola, mas também as que o docente realiza em sala de aula cujo foco está na aprendizagem de seus alunos. Essa compreensão focaliza majoritariamente os resultados educacionais, quer seja no âmbito do sistema nacional de avaliação ou, mesmo, no espaço da sala de aula. Busca-se construir consenso em torno da importância de criar um ambiente em que a superação das metas educacionais seja compromisso de todos, mas responsabilidade do professor e da gestão da escola.

Em conta da amplitude do conceito de accountability, temos que as políticas educacionais tendem a ressemantizar o vocabulário da reforma segundo a lógica predominante. Tendente à construção de um pensamento hegemônico em torno das mudanças consideradas necessárias ao aparato do Estado, os vocábulos conexos às ferramentas de accountability e recorrentes nos documentos da política para a educação básica buscam escamotear o consenso que pretendem forjar no alcance dos objetivos político-ideológicos do capitalismo na sua fase mais avançada, ao passo 
que se apropriam de um discurso em favor da participação, da transparência e do controle social e o utilizam em prol das mudanças estruturais ensejadas, multiplicam espaços de organização da sociedade civil sob os auspícios do Estado.

\section{Considerações finais}

Considerado um conceito fundamental nas sociedades democráticas, o entendimento sobre a accountability parece sofrer de uma eterna imprecisão semântica. Prevalece uma ideia vaga de seu significado, mas com poucas evidências de como concretizá-lo no campo empírico. A ascensão desse tema à política educacional coincide com o surgimento da moderna administração pública, em que o controle interno e externo das instituições, a prestação de contas e a responsabilidade política ganham a cena. Nesse contexto específico, o uso dessa expressão suplanta a dimensão institucional formal da prestação de contas e da imputação de consequências (positivas ou negativas) e passa a ser relacionado aos processos políticos mais amplos nos quais sobressai o conceito de participação democrática.

Coerente com o léxico da política educacional patrocinada por agências multilaterais, nesse campo o conceito de accountability tem sido utilizado de forma redutora para referir-se às relações de poder entre o Estado, as instituições educativas e a sociedade. Trata-se, pois, de uma visão unidimensional do conceito com centralidade no Estado.

A análise do vocabulário das políticas para a educação básica possibilitou compreender que a discursividade dos documentos da reforma educacional, no Brasil, vaticina tendência à construção de uma ideia de participação circunscrita ao espaço da escola, mais diretamente nas questões atinentes à gestão do pedagógico. Ainda que evoquem diferentes atores, dispositivos e finalidades, os propósitos a que se destinam os espaços de participação possuem alcance predominantemente intrainstitucional. Os espaços institucionais de participação e as finalidades a que 
se remetem pouco contribuem para fortalecer a consciência política dos cidadãos, consoante a concepção contemporânea de democracia.

Ainda que possamos considerar fundamental a construção desses espaços para a deliberação coletiva, está em causa a efetividade deles na construção de uma consciência política sobre o controle e o poder de decisão. Apesar de reconhecermos a ampliação de desenhos institucionais participativos no Brasil, consideramos que o poder decisório permanece sob o guarda-chuva do governo central, restando incerta a conformação e o alcance de uma accountability democrática em nosso país.

\section{Referências}

AFONSO, A. J. Avaliação Educacional: regulação e emancipação. 4. ed. São Paulo: Cortez, 2009. 151 p.

AFONSO, A. J. Gestão, autonomia e accountability na escola pública portuguesa: breve diacronia. RBPAE, São Paulo, v. 26, n. 1, p. 13-30, jan./abr. 2010.

BARDIN, L. Análise de conteúdo. Lisboa: Edições 70, 1995.

BOVENS, M. Analysing and assessing accountability: a conceptual framework. European Law Journal, v. 13, n. 4, p. 1-37, jan. 2006. Disponível em: <https:// www.ihs.ac.at/publications/lib/ep7.pdf>. Acesso em: 28 mar. 2018.

BROOKE, N. O futuro das políticas de responsabilização social no Brasil. Cadernos de Pesquisa, v. 36, n. 128, p. 377-401, maio/ago. 2006. Disponível em: <http://www.scielo.br/pdf/\%0D/cp/v36n128/v36n128a06.pdf >. Acesso em: 28 mar. 2018.

CENEVIVA, R. Accountability: novos fatos e novos argumentos - uma revisão da literatura recente. In: ENCONTRO DE ADMINISTRAÇÃO PÚBLICA E GOVERNANÇA, 30., 2006, São Paulo. Anais... São Paulo: ANPAD, 2006. p. 1-17.

DAHL, R. Democracy and its Critics. New Haven: Yale University Press, 1989. 
FERREIRA, L. S. Gestão do pedagógico: de qual pedagógico se fala? Currículo Sem Fronteiras, v. 8, n. 2, p. 176-189, jul./dez. 2008.

KENNEY, C. D. Horizontal accountability: concepts and conflicts. In: MAINWARING, S.; WELMA, C. Democratic accountability in Latin America. Oxford: Oxford Studies in Democratization, 2003.

JAMESON, F. Pós-modernismo: a lógica cultural do capitalismo tardio. 2. ed. São Paulo: Ática, 1997.

MALENA, C.; FORSTER, R.; SINGH, J. Social accountability: an introduction to the concept and emerging practice. Social development paper, n. 76, dec. 2004.

MANIN, B.; PRZEWORSKI, A.; STOKES, S. C. Eleições e representação. Trad. Felipe Duch. Lua Nova, São Paulo, n. 67, p. 105-138, 2006.

MORENO, E.; CRISP, B. F.; SHUGART, M. S. The accountability deficit in Latin America. In: MAINWARING, S.; WELMA, C. Democratic accountability in Latin America. Oxford: Oxford University Press, 2003.

O’DONNEL, G. Accountability horizontal e novas poliarquias. Lua Nova, n. 44 [online], p. 27-54, 1998. Disponível em: <http://www.scielo.br/pdf/ln/n44/ a03n44.pdf>. Acesso em: 03 mar. 2018.

RISCAL, S. A.; GANDINI, R. P. C. Notas sobre o conceito de participação política e sua articulação com a concepção de gestão democrática. Revista Eletrônica de Educação, São Carlos, v. 4, n. 2, p. 50-69, nov. 2010. Disponível em: <http://www. reveduc.ufscar.br/index.php/reveduc/article/view/176/102>. Acesso em: out. 2018.

SÁ, V. A (não) participação dos pais na escola: a eloquência das ausências. In: FONSECA, M.; VEIGA, I. P. A. (Orgs.). As dimensões do projeto político-pedagógico: novos desafios para a escola. Campinas: Papirus, 2001.

SCHEDLER, A. ¿Qué es la rendición de cuentas? IFAI: Delegación Coyoacán C. P., 2004. 
SCHNEIDER, M. P.; NARDI, E. L. Accountability em educação: mais regulação da qualidade ou apenas um estágio do Estado-avaliador? ETD - Educação Temática Digital, Campinas, v. 17, n. 1, p. 58-74, jan./abr. 2015.

SHIROMA, E. O.; CAMPOS, R. F.; GARCIA, R. M. C. Decifrar textos para compreender a política: subsídios teórico-metodológicos para análise de documentos. Perspectiva, Florianópolis, v. 23, n. 2, p. 427-446, jul./dez. 2005.

VERA, E. I.; LAVALLE, A. G. Arquitetura da participação e controles democráticos no Brasil e no México. Trad. José Szwako e Liliana Sanjuro. Novos Estudos, n. 92, p. 105-121, mar. 2012.

\section{Documentos consultados}

BRASIL. Portaria n ${ }^{\circ}$ 931, de 21 de março de 2005. Diário Oficial da União, Seção 1, n. 55. Brasília, 22 de março de 2005.

BRASIL. Decreto n 6.094, de 24 de abril de 2007. Implementação do Plano de metas Compromisso Todos pela Educação. Diário Oficial Executivo, Brasília, DF, 25 abr. 2007.

BRASIL. Resolução $n^{\circ}$ 5, de 17 de dezembro de 2009. Fixa as Diretrizes Curriculares Nacionais para a Educação Infantil. Diário Oficial da União, Brasília, 18 de dezembro de 2009. Seção 1, p. 18.

BRASIL. Conselho Nacional de Educação. Câmara de Educação Básica. Resolução $\mathrm{n}^{\circ}$ 4, de 13 de julho de 2010. Fixa as Diretrizes Curriculares Nacionais Gerais para a Educação Básica. Diário Oficial da União, Brasília, 14 jul. 2010a. Seção 1, p. 824 .

BRASIL. Resolução $n^{\circ}$ 7, de 14 de dezembro de 2010. Fixa as Diretrizes Curriculares Nacionais para o Ensino Fundamental de 9 (nove) anos. Diário Oficial da União, Brasília, 15 dez. 2010b, Seção 1, p. 34. 
BRASIL. Conselho Nacional de Educação. Câmara de Educação Básica. Resolução $\mathrm{n}^{\circ}$ 2, de 30 de janeiro de 2012. Fixa as Diretrizes Curriculares Nacionais para o Ensino Médio. Diário Oficial da União, Brasília, 31 jan. 2012. Seção 1, p. 20.

BRASIL. Ministério da Educação. Secretária de Educação Básica. Diretoria de Currículos e Educação Integral. Diretrizes Curriculares nacionais gerais para a educação básica. Brasília: MEC, SEB, DICEI, 2013. 542p.

BRASIL. Lei $n^{\circ}$ 13.005, de 25 de junho de 2014. Aprova o Plano Nacional de Educação - PNE e dá outras providências. Diário Oficial da União, Brasília, 26 jun. 2014. Edição Extra, p. 1.

Recebido: 11/10/2018

Received: 10/11/2018

Recibido: 11/10/2018

Aprovado: 03/12/2018

Approved: 12/03/2018

Aprobado: 03/12/2018 